\title{
Moving into the next phase of the Journal of Developmental and Life-Course Criminology: Editorial Introduction
}

\author{
Tara Renae McGee ${ }^{1} \cdot$ Paul Mazerolle ${ }^{2} \cdot$ Darrick Jolliffe $^{3} \cdot$ Manuel Eisner $^{4}$
}

Published online: 17 November 2021

(c) The Author(s), under exclusive licence to Springer Nature Switzerland AG 2021, corrected publication 2022

The origins of the Journal of Developmental and Life-Course Criminology (JDLCC) date to 2014 when we began working with Springer to establish this journal for the Division of Developmental and Life-Course Criminology, a Division of the American Society of Criminology (ASC). Anchoring the JDLCC to a division of the ASC made perfect sense to us. The Division represented the largest collection of developmental and life-course criminologists across the globe and included the vast majority of leading thinkers in this field of scholarship. Moreover, there was a large group of very supportive senior scholars who agreed that this was an idea worth pursuing.

As readers of this introduction can no doubt appreciate, building a journal from scratch is no easy feat. Our intention has always been to build a high-quality outlet for research which would facilitate the advancement of developmental and lifecourse criminology globally.

From a standing start, we needed to establish protocols and procedures for all aspects of the review and editorial processes. Moreover, we needed to establish a supportive, distinguished and expert editorial board. As we enter the horizon of our term as the inaugural co-editors of the JDLCC, it is important for us to recognise and thank the entire editorial board who leant their support and expertise to the success of the journal. The support was there from the start, and we deeply appreciate the assistance of the board.

Tara Renae McGee

t.mcgee@griffith.edu.au

$\triangle$ Darrick Jolliffe

d.jolliffe@greenwich.ac.uk

1 Griffith Criminology Institute, Griffith University, Brisbane, Australia

2 University of New Brunswick, New Brunswick, Canada

3 University of Greenwich, London, UK

4 University of Cambridge, Cambridge, UK 
We also thank the broader developmental and life-course criminology community for consistently submitting their work to the journal and for agreeing to review manuscripts.

There have been many highlights across the past 7 years. In our initial issue, we stressed the importance of embracing an age-graded approach to understanding the development of offending and related behaviours across the life-course. Moreover, our goal from the start was to ensure that the JDLCC became an outlet for attracting high quality manuscripts to best ensure that the journal became recognized as a high-quality outlet for research.

To advance the value of the JDLCC, we brought in a number of innovations. For example, drawing on the tradition in epidemiology of publishing cohort profiles, we encouraged members of our community to submit cohort profiles for all the longitudinal criminology studies around the world. This is ongoing and we encourage colleagues of studies who have not published cohort profiles to submit them to the new editors. Additionally, with the annual Lifetime Achievement Award offered by the Division of Developmental and Life-Course Criminology, we have been able showcase the recipients who received the award and delivered the David P. Farrington Lecture at the annual meeting of the American Society of Criminology conference. Beginning in 2017, we have been privileged to be able to publish this important annual lecture delivered by the leading developmental and life-course criminologists from around the globe.

We also embraced themed special issues as an important feature for the JDLCC. The opportunity to include manuscripts around a unique theme or aspect of developmental and life-course criminology has been well received. Topics for special themed issues included desistance, developmental and life-course approaches to prevention, methodological innovations in developmental and life-course criminology, gendered experiences in developmental pathways and theories of offending across the life-course. Many of these manuscripts represented seminal contributions and some served to generate further debate and dialogue. We have dedicated space and opportunity in the JDLCC for these ongoing discussions to occur, in part because these debates and commentaries serve to ultimately advance our understanding of offending across the life-course.

In 2018, Springer registered the JDLCC in the Emerging Sources Citations Index which was a precursor to applying to Clarivate Analytics to have the journal considered for inclusion in the impact factor rankings for Criminology in Penology. When the journal first appeared in the rankings in 2019, its 2-year impact factor was 1.133. By 2020, the impact factor jumped up to 2-year: 2.360; 5-year: 3.313; difference: +1.227 . As editors, we are very proud of this result because it represents one important indicator of the quality of the JDLCC. We acknowledge that these very positive results have been made possible by the collective good will and hard work of developmental and life-course criminologists from around the world.

As our work as editors of the JDLCC comes to an end, we reiterate our thanks for the opportunity as well as for the ongoing support which has been critical for shaping the current success of the journal. We know the JDLCC is in good hands as it transitions to Darrick Jolliffe and Manuel Eisner and we will watch with interest as they take it forward into exciting new directions in the years ahead. 
As the incoming editors, we were very honoured to be selected to take over the editorial responsibilities from Paul and Tara for the JDLCC. It is very humbling to see what they have accomplished in such a short period of time, and while we recognise that it will be a challenge to follow this impressive legacy, we are truly committed to continuing the JDLCC on its steep upward trajectory. The JDLCC is now a preeminent outlet for high-quality and impactful research on developmental criminology and we intend to keep it that way.

In order to achieve this, we of course, will be relying heavily on our dedicated reviewers and our Editorial Board. We will shortly be refreshing our Editorial Board to ensure that we have the diversity and range of experiences and knowledge to help us move the JDLCC forward. We hope that we can wish departing members of the Editorial Board well, and welcome new Editorial Board members in-person at the American Society of Criminology meeting in Chicago in November. However, we recognise that coronavirus has made attendance at such conferences particularly challenging, which is why we are aiming to have a virtual Editorial Board meeting in early October. This would be an opportunity to discuss the future directions of the JDLCC and to hear ideas that you might have for future special issues and for the general growth of the Journal.

The current scope of the journal is such that it welcomes contributions from cognate disciplines but in reality, much of what is published in the JDLCC comes from criminologists. We are very keen to encourage more contributions from related disciplines such as economics and mental health as well as cross-disciplinary and multi-disciplinary research. This is why we are proposing our first Special Issue will be requesting contributions related to the complex relationship between mental health and offending across the life-course. Please watch for this imminent call.

We would also like to introduce Simone Castello who will be acting as our Managing Editor. Simone has a background in journalism and digital marketing and has recently done a fantastic job at using social media platforms to highlight the work of the Violence Research Centre based at Cambridge University. Simone will be helping us manage the JDLCC but will also have a role in expanding the reach of the journal and its publications on social media platforms.

We would like to take this opportunity to thank Paul and Tara for all their hard work on the JDLCC and wish them well in the future.

Publisher's Note Springer Nature remains neutral with regard to jurisdictional claims in published maps and institutional affiliations. 